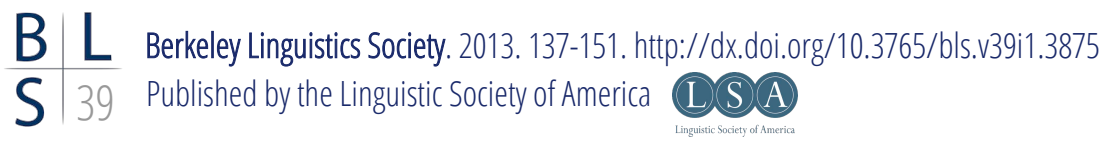

\title{
The Topic-Comment Structure in Copular Sentences: Evidence from Wolof*
}

\author{
MARTINA MARTINOVIĆ \\ University of Chicago
}

\section{Introduction}

This paper investigates the syntax of information structure of Double-DP copular sentences in Wolof, a Niger-Congo language spoken primarily in Senegal. English copular sentences of the structure $D P$ be $D P$ are classified into several types. The most discussed distinction is the one between predicational sentences, as in (1), and specificational sentences, as in (2).

(1) [DP1 Carissa ] is [DP2 a mother ].

[PREDiCATIONAL]

(2) $[D P 1$ The department chair ] is [DP2 Chris ].

[SPECIFICATIONAL]

The two sentences differ in several ways. First, while the post-copular DP (DP2) in a predicational sentence predicates a certain property of a discourse referent established by the pre-copular DP (DP1), in a specificational sentence DP2 provides a value for a variable introduced by DP1. Furthermore, it is proposed that different copular sentences are associated with different information-structural properties. In particular, specificational sentences are claimed to obligatorily focus the postcopular constituent (Higgins 1979; Declerck 1988; Mikkelsen 2005, etc.), while predicational sentences carry no such requirements.

*I am grateful to Itamar Francez and Karlos Arregi for numerous discussions of this topic, and to the audience at BLS 38 for useful feedback. All mistakes are my own. 


\section{Martina Martinović}

The typology of copular sentences is mostly based on the study of these constructions in English and several other Germanic languages. To determine whether properties associated with different copular sentence types are universal (and consequently, whether there can even be talk of a cross-linguistic typology), it is important to investigate languages in which some of the claims can be tested.

In this paper, I discuss some properties of Double-DP copular sentences in Wolof, a Niger-Congo language which can greatly contribute to our understanding of the syntax and information structure of copular sentences. Wolof marks information-structural phenomena in the morpho-syntax: focused constituents $\mathrm{A}^{\prime}$ move to a designated position in the clause, and topicalized phrases are leftdislocated and resumed by a pronoun. Both phenomena are apparent in copular sentences, making it possible to study the relationship between the function and structure of copular sentences. I show that the information-structural properties of Wolof copular sentences are not only apparent, but that they have a direct influence on available copular sentence types, in restricting the types of DPs that can occupy DP1 and DP2 position. Furthermore, the Wolof data show that claims about the function and usage of copular sentences based on English and several other Germanic languages need to be reevaluated against data from languages which use different strategies in forming copular sentences.

The paper is organized as follows. In $\S 2$, I discuss types of copular sentences and the information-structural properties usually associated with them. I review the relevant properties of Wolof clausal structure in $\S 3$. I introduce the data from Wolof copular sentences in $\$ 4$, and investigate different DP types that occur in different copular sentence structures. In $\S 5$, I propose an analysis of the interaction between information-structural properties of copular sentences and DP types that they allow. I conclude the paper in $\S 6$.

\section{Copular Sentences}

\subsection{Types of Copular Sentences}

Copular sentences contain two constituents usually connected with a copula. This paper only deals with copular sentences in which the constituents are two DPs, as in (3), which I refer to as Double-DP sentences.
a. Tim is a lawyer.
b. The professor is Karlos.

One of the first detailed investigations of copular sentences was undertaken by Higgins (1979). Following Akmajian (1970), Higgins highlights a distinction between the predicational and the specificational meaning of copular sentences. Consider the following examples: 


\section{The Topic-Comment Structure in Copular Sentences: Evidence from Wolof}

(4) a. $[D P$ Bernard Haitink $]$ is $[D P$ an exquisite musician]. [predicational]

b. [DP The main conductor] is [DP Bernard Haitink]. [specificational]

In (4a), the pre-copular DP (DP1) denotes an individual, and the post-copular DP (DP2) predicates a property of that individual: there is an $x$ (Bernard Haitink), and that $x$ has the property of being an exquisite musician. Specificational sentences, as the one in (4b), seem to perform a different function: the precopular constituent provides a variable (there is an $x$ such that $x$ is a main conductor), and the postcopular constituent provides a value for that variable $(x=$ Bernard Haitink) (Higgins 1979; Declerck 1988; den Dikken 2001; Mikkelsen 2005). The value is new information, or focus, and the variable part is old information, presupposition (Declerck 1988), or topic (Mikkelsen 2005). In that sense, a specificational sentence is akin to question-answer pairs, in that the value provides the answer to the question contained in the variable (Declerck 1988).

In addition to predicational and specificational sentences, another type is relevant for the present discussion:

(5) The ficus elastica is the rubber plant.

In the sentence in (5), both DPs seem to be referential, and the referent of DP1 is equated with the referent of DP2. Such sentences are usually called equatives or identity statements (Higgins 1979; Heggie 1988; Declerck 1988).

It is claimed that the crucial difference between predicational and specificational sentences is in the type of the structural subject (the constituent in Spec,TP), which is referential in predicational, and non-referential in specificational sentences (Higgins 1979; Heggie 1988; Declerck 1988; Mikkelsen 2005). It is uncontroversial that DP1 is referential and DP2 property-denoting in predicational sentences, as in (4a). The situation in specificational sentences is less straightforward. That DP2, usually being a name, is referential, is quite clear, but the semantic type of DP1 is a matter of debate. Mikkelsen (2005) uses various tests to elucidate the difference between predicational and specificational subjects, ${ }^{1}$ one of which is the contrast in pronominalization pattern of DP1 in these two sentence types:

(6) a. The tallest girl in the class is Swedish, isn't $\{$ she/*it $\}$ ? [predicational] b. The tallest girl in the class is Molly, isn't it? [specificational]

Specificational subjects (DP1's) are pronominalized with the impersonal pronoun it in tag questions, unlike predicational subjects. Mikkelsen thus argues that specificational subjects are properties, of type $\langle e, t\rangle$. A different view is advocated in Romero 2005: the constituent in Spec,TP in specificational sentences is an individual concept (of type $\langle s, e>$ ). Her claim is, among other, based on the same

\footnotetext{
${ }^{1}$ In this paper, subject is used to refer to the constituent in Spec-TP.
} 


\section{Martina Martinović}

pronominalization pattern discussed in Mikkelsen 2005: tag questions in the concealed question in (7b) (which she considers to be individual concepts) and the specificational sentence in (7a) uses the same (inanimate) pronoun it:

(7) a. The girl who caused the trouble wasn't Mary. It/*She was Jane.

b. John guessed the winner of the Oscar for best actress before I guessed it/*her.

The debate about the semantic type of DP1 in specificational sentences is not settled. However, it is clear that it is not a referential DP.

\subsection{Information Structure of Copular Sentences}

Most authors notice that, unlike predicational sentences, specificational ones have a particular information structure: the variable is the presupposition, old information, or topic, and the value is the focus of the sentence (Higgins 1979; Declerck 1988; Heycock 1994; Mikkelsen 2005). Consider the following question-answer pairs:

(8) a. Who is the winner?

b. The winner is JoHn. (S)

c. JOHN is the winner. $(\mathrm{P})$
(9) a. What is John?

b. \#The WINNER is John. (S)

c. John is the WINNER. (P)

A question about the subject (i.e. a question which focuses the referential DP) can felicitously be answered with either a predicational sentence, or a specificational sentence. A question which requires the non-referential DP to be focused, however, can only be answered with a predicational sentence; a specificational sentences seems to reject focus on the pre-copular DP. Based on examples in (8) and (9), Mikkelsen (2005) (also Heycock 1994) argues that specificational sentences in English have a fixed topic-focus structure: DP1 is obligatorily the topic, and DP2 the focus. No similar requirements are placed on predicational sentences.

Wolof overtly marks information-structural properties: topicalization and focalization are expressed in the morpho-syntax, which makes it an ideal candidate for the study of the universality of claims made in the taxonomy of copular sentences.

\section{The Clause Structure and $\mathbf{A}^{\prime}$-movement in Wolof}

Wolof belongs to the Atlantic branch of the Niger-Congo language family, most widely spoken in Senegal, but also in the Gambia and Mauritania. It is an SVO language, as shown in the neutral, affirmative sentence in (10):

(10) Xale yi jox na-ñu Musaa tééré bi. child the give $\mathrm{C}_{A F F}-3$ PL Musa book the "The children gave Musa the book." 


\section{The Topic-Comment Structure in Copular Sentences: Evidence from Wolof}

This basic word order is changed in $\mathrm{A}^{\prime}$-movement structures, such as focus constructions, in which the extracted element is fronted:

(11) Tééré bi 1-a xale yi jox Musaa.

book the $l-\mathrm{C}_{W H}$ child the give Musa

"The children gave [THE BOOK] FOC to Musa."

[OBJECT FOCUS]

Aside from word order, (10) and (11) differ in two more ways. First, in both sentences there is another element in the clause, a sentential particle, in addition to the subject, the verb, and the object - na in the affirmative sentence, and la in the object focus sentence. Second, an element which I refer to as the subject marker follows the particle $n a$ in (10) ( $\tilde{n} u, 3 \mathrm{PL})$, but is absent in (11).

There are about a dozen different sentence particles in Wolof: subject and complement focus particles, imperative, affirmative, obligative and negative imperative/obligative particles, and four different temporal modality particles. Due to their complementary distribution, Dunigan (1994) assumes that all sentential particles occupy a single position in the clause, which she identifies as the Sigma phrase, following Laka (1990). For the present purposes, it is sufficient to know that the particles occupy a projection immediately dominating the TP. Since they are complementizer-like elements, I assume the particles are located in C.

In (10), a subject marker follows the clausal particle $n a$, but it is altogether absent in (11). There are two groups of construction with respect to the occurrence of subject markers. In $\mathrm{A}^{\prime}$-movement structures, the subject markers are in complementary distribution with lexical subjects. (12) shows an object focus sentence, in which the object is fronted to the left of the complementizer, and either the lexical subject or the subject marker are found to the right of the complementizer; they cannot both occur (examples from Dunigan 1994).
a. Modu l-a góón ñi gis
Modu $l-\mathrm{C}_{W H}$ man the see
b. Modu l-a-ñu gis Modu $l-\mathrm{C}_{W H}-3$.PL see
"They saw $[\mathrm{MODU}]_{F O C} . "$ "The men saw $[M O D U]_{F O C .}$.
c. *Modu l-a-ñu góór ñi gis Modu $l$ - $\mathrm{C}_{W H}$-3.PL man the see

The lexical subject and the subject marker can both be present only is if the lexical subject precedes the focused element. In fact, the subject marker is obligatory in that case, suggesting that it is a pronoun resuming a topicalized lexical subject:
a. Góór ñi Modu l-a-ñu gis man the Modu $l-\mathrm{C}_{W H^{-}}$-3.PL see "The men, they saw $[M O D U]_{F O C . "}$
b. *Góór ñi Modu l-a gis men the Modu $l-\mathrm{C}_{W H}$ see 


\section{Martina Martinović}

The second type are structures are those in which only the subject marker can follow the sentence particle, and the lexical subject is obligatorily at the left edge of the clause. Consider the examples of neutral affirmative sentences in (14):
a. Lekk na-ñu ceep. eat $\mathrm{C}_{A F F}$-3.PL rice "They ate rice."
b. Xale yi lekk na-ñu ceep. child the eat $\mathrm{C}_{A F F}-3$. PL rice "The children ate rice."
c. *Lekk na xale yi ceep. eat $\mathrm{C}_{A F F}$ child the rice
d. *Xale yi lekk na ceep. child the eat $\mathrm{C}_{A F F}$ rice

Dunigan (1994) and Russell (2006) consider these lexical subjects to be topicalized and resumed by a pronoun in Spec,TP. Russell (2006) presents evidence to that effect, illustrating that left-dislocated lexical subjects in many ways behave like other topics in Wolof. I follow this analysis.

The examples of $\mathrm{A}^{\prime}$-movement constructions in (11)-(13) all contain the sentence particle $(l) a$. Most instances of $\mathrm{A}^{\prime}$-movement (focus constructions, one type of wh-questions, comparatives, and all long-distance extraction) require its presence. Building on previous work (Martinović 2013), I analyze ( $l$ ) $a$ as an $\mathrm{A}^{\prime}$ movement complementizer. An important property of this complementizer is that it exhibits a subject/non-subject asymmetry: it surfaces as $a$ in cases of subject extraction, as in (15), and as la in cases of non-subject extraction, in (16) (Torrence 2005, 2013a,b; Martinović 2013).
$\mathrm{K}$-an a gis Musaa?
CL-an $\mathrm{C}_{W H}$ see Musa
"Who saw Musa?"
(16) K-an l-a Musaa gis?
CL-an l- $\mathrm{C}_{W H}$ Musa see
"Who did Musa see?"

The two discussed phenomena - obligatory left-dislocation of lexical subjects and the syntax of $\mathrm{A}^{\prime}$-movement - are crucial for understanding the structure and properties of Double-DP copular sentences in Wolof, which are $\mathrm{A}^{\prime}$-movement constructions, some of which obligatorily left-dislocate their lexical subjects.

\section{Double-DP Copular Sentences in Wolof}

Double-DP copular sentences do not contain a copula, but they do contain one of the sentence particles: the $\mathrm{A}^{\prime}$-movement complementizer (l)a. They come in two forms, DP DP la-SM, or DP- $a$ DP, illustrated in (17) and (18), respectively. This paper mostly discusses the first type, which I call la-sentences.

(17) Xale yi sacc 1-a-ñu. child the thief $l$-C-3PL "The children are thieves."
(18) Saamba a di (>Saambai) sacc. Samba C PRES thief "Samba is a thief." 


\section{The Topic-Comment Structure in Copular Sentences: Evidence from Wolof}

The presence of (l)a always involves $\mathrm{A}^{\prime}$-movement of a constituent to its specifier position. ${ }^{2}$ The form of the complementizer in (17) tells us that the DP in its specifier, sacc, did not move there from Spec,TP, meaning that xale yi is the structural subject of the sentence. Furthermore, in the la-sentence, the particle is obligatorily followed by a subject marker. We saw that there are structures in Wolof in which the lexical subject is obligatorily left-dislocated, and resumed by a subject marker. It appears that $l a$-sentences are another such case.

In the $a$-sentence in (18), the complementizer surfaces as $a$, indicating that the element in its specifier is the structural subject. The predicate DP remains below the particle, and there is no resumption.

One difference between $l a$-sentences and $a$-sentences lies in their use: while the former are felicitous in a neutral and out-of-the-blue context, the latter usually require DP1 to be focused. I return to this point briefly in $\S 5$. A difference more pertinent to the present discussion is that $l a$-sentences restrict the types of DPs that can occur as DP1 and DP2, while a-sentences do not. I therefore mostly focus on the properties of $l a$-sentences.

A tentative structure of the $l a$-sentence and the a-sentence from (17) and (18) is presented in (19) and 20, respectively. I assume that the two DPs are start out in a small clause. Since Wolof does not have an overt copula, I do not include a VP node in the representation for sake of simplicity. In (19), DP1 raises to Spec,TP, and either moves to Spec,TopP and is resumed in Spec,TP, or stays in Spec,TP and is co-indexed with a lexical subject base-generated in Spec,TopP. DP2 moves to Spec,CP. ${ }^{3}$ In (20), DP1 moves to Spec,TP and then to Spec,CP. DP2 stays in situ. ${ }^{4}$

\subsection{DP Types in $l a$-sentences}

Copular sentences in English differ in terms of the semantic types of DPs that occupy DP1 and DP2 position. Furthermore, we have seen that there seem to be information-structural differences between different types of copular sentences in English. Since Wolof marks information-structural properties in the morpho-

\footnotetext{
${ }^{2}$ Some authors consider (l)a to be a copula (Kihm 1999; Torrence 2005, 2013a,b), due to its occurrence in copular sentence. However, it is not uncommon for elements other than the copula, such as focus markers in African languages (c.f. Hausa, Green 2007) to appear in copular sentences. More importantly, ( $l$ ) $a$ in no way behaves like a verbal element in Wolof: it does not occupy a position inside the VP, but occurs in a projection above the TP, and it is in complementary distribution with all other sentence particles (i.e. complementizer-like elements). For a detailed discussion, see Martinović 2013.

${ }^{3}$ An obvious question to ask is why the predicate DP would obligatorily move to the specifier of the complementizer $(l) a$, which usually occurs in focus constructions, in a neutral copular sentence. While this is an important question, I do not address it here.

${ }^{4}$ Another difference between the two structures is in the obligatory absence of the present tense marker in a la-sentence, and its obligatory presence in an a-sentence. I leave this issue for further research.
} 


\section{Martina Martinović}

(19)

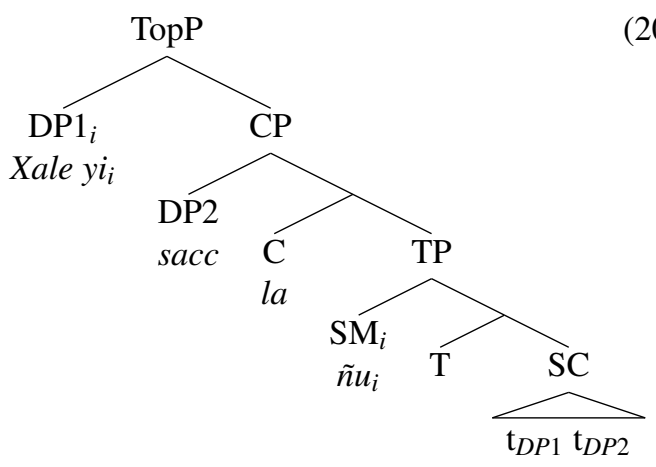

(20)

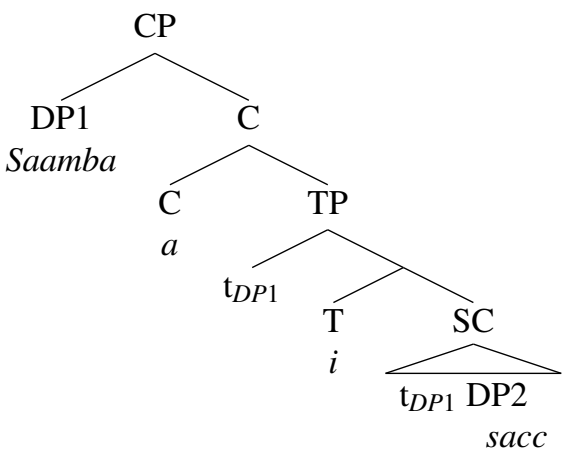

syntax, it is a good candidate for investigating the properties of copular sentences that seem to hold for English. In this section, we explore DP types that can occur in Wolof $l a$-sentences. Since all types of DPs are allowed in $a$-sentences, I do not address them in detail here.

Both names and definite descriptions are felicitous in DP1 position, with an indefinite DP in DP2 position, corresponding to English predicational sentences:

Saamba sacc $1-a-\emptyset$.

Samba thief $l$-C-3SG.

"Samba is a thief."
(22) Jangalëkat bi sacc 1-a- $\emptyset$.

teacher the thief $l-\mathrm{C}-\emptyset$

"The teacher is a thief."

In English, it is also possible for a definite DP to occupy the post-copular position in this type of a copular sentence:
a. Samba is a thief.
b. Samba is the thief.

There are at least two possible interpretations of the sentence Samba is the thief. In one scenario, there is a room full of criminals, and we know that only one of them is a thief. The assertion Samba is the thief then identifies Samba as being the one who has the property of being a thief. On another reading, there is a particular person (who, for example, was the first to steal the Crown Jewels) and this assertion identifies him as a specific individual, Samba. These two readings are respectively identified as attributive and referential in Donnellan 1966.

In Wolof, a definite DP is not felicitous as DP2 of a la-sentence if it is meant to denote a property. A question such as What is Samba? in a context such as the one described above, where Samba is the only thief in a room full of people (so that being a thief is considered Samba's occupation, and is not referring to him as a perpetrator of a specific theft), cannot be answered with the sentence in (24). ${ }^{5}$

\footnotetext{
5 The sentence in (24) is felicitous only if Samba is being singled out among a group of individuals as the person who committed a particular theft. I return to this point in $\S 5$.
} 


\title{
The Topic-Comment Structure in Copular Sentences: Evidence from Wolof
}

\author{
\#Saamba sacc bi $1-a-\emptyset$. \\ Samba thief the $l-\mathrm{C}-3 \mathrm{SG}$ \\ "Samba is the thief."
}

It seems that in predicational sentences in Wolof, the DP denoting a property can only be indefinite. This could mean that definite descriptions do not denote properties in Wolof, i.e. that they are not of type $<e, t>{ }^{6}$

A definite DP is acceptable in DP2 position in a context such as the following. A robbery was committed in a village, and the police found a teacher's notebook at the scene of the crime. There is only one teacher in the village, so they conclude that the perpetrator of the robbery is the village teacher. DP2 in this example can felicitously be substituted by a name:

(25) Sacc bi jangalëkat bi $1-a-\emptyset$. thief the teacher the $l-\mathrm{C}-3 \mathrm{SG}$ "The thief is the teacher."
(26)

Sacc bi Saamba l-a- $\emptyset$. thief the Samba $l-\mathrm{C}-3 \mathrm{SG}$ "The thief is Samba."

The constructions in (25) and (26) are like specificational sentences in English: DP1 contains a variable, and DP2 provides the value for it (in Higgins' sense). It is not clear what the semantic type of definite DPs in DP1 position in (25) and (26) is. However, we have seen that a definite DP cannot occupy DP2 position when it would have to denote a property. This could indicate that in Wolof, at least some definite descriptions can not be of type $\langle e, t\rangle$.

Another possibility is that both DPs in (25) and (26) are of type $e$, and that the examples in (25) and (26) are identity statements, such as The ficus elastica is the rubber plant. However, example (27) shows that both DPs in a la-sentence cannot be referential. Identity statements such as Osman is Samba (meaning that the person who introduces himself as Osman is also the person who introduces himself as Samba) cannot be expressed with a la-sentence.

\section{*Osmaan Saamba 1-a-Ø. \\ Osman Samba $l-\mathrm{C}-3 \mathrm{SG}$ \\ intended: "Osman is Samba."}

In $a$-sentences, all DPs are allowed in all positions. As already mentioned, the main difference between la-sentences and a-sentences is in their use: the former ones are felicitous in neutral, out-of-the-blue contexts, while the latter ones usually require DP1 to be focused. However, in cases in which a particular structure cannot be expressed with a la-sentence, such as the ones in (24) and (27), corresponding $a$-sentences are used, regardless of the position of focus.

${ }^{6}$ This phenomenon has been observed in other languages as well. Adger and Ramchand (2003) discuss the case of Scottish Gaelic, in which definite DPs cannot be found in the same type of predicational sentences as indefinite DPs. This also appears to be the case in Salish (Matthewson 1996). 


\section{Martina Martinović}

(28) Saamba a di ( $>$ Saambaai) sacc bi.

Samba C PRES thief the

"Samba is the thief."

(29) Osmaan a di (> Osmaanai) Saamba.

Osman C PRES Samba

"Osman is Samba."

Table 30 summarizes the discussion on DP types in la-sentences in Wolof, and ties them to the known types of copular sentences in Germanic.

DP types in la-sentences

\begin{tabular}{ll|l|l}
\multicolumn{2}{c|}{ SENTENCE TYPE } & DP1 & DP2 \\
\hline \hline$\sqrt{ }$ & PREDICATIONAL & name, definite DP & indefinite DP, *definite DP \\
\hline$\sqrt{ }$ & SPECIFICATIONAL & definite DP & definite DP, name \\
\hline$*$ & INDENTITY & name & name
\end{tabular}

The possibility for all DP types to occupy any position in $a$-sentences shows that such structures are not incompatible with copular sentences in general. This means that there is something about $l a$-sentences which makes certain DP combinations, and consequently certain copular sentence types, impossible. In the following section, I propose that $a$-sentences and $l a$-sentences differ in information-structural properties, which are the result of their different syntactic structures.

\section{The Topic-Comment Structure of $l a$-sentences}

In section $\S 4$, it is shown that $l a$-sentences have an informational-structural property which $a$-sentences do not share: they have obligatorily topicalized subjects. This results in a topic-comment structure, which has the purpose of attributing some property (comment) of an already established discourse referent (topic) (Lambrecht 1994). I propose that this syntactic configuration forces the two DPs in copular sentences to be asymmetric: DP2 must contribute information about DP1. For the purposes of the present discussion, we can frame the requirement for DP2 to contribute information about DP1 in another manner: DP1 introduces a question which DP2 (partially) answers. If we think about the two DPs as being in a question-answer relationship, we need to identify possible questions that can be asked. Let us look at two scenarios that capture the structure of the copular sentences investigated in this paper. In the first one, DP1 is a name, and in the second one, DP1 is a definite description.

\subsection{DP1 is a Name}

In predicational sentences and identity statements, DP1 can be a name. In predicational sentences in English, DP2 can then be an indefinite or a definite DP. Identity 


\section{The Topic-Comment Structure in Copular Sentences: Evidence from Wolof}

statements can contain either a name or a definite description as DP2, as long as it is referential. We have seen that specificational sentences do not have a name in DP1 position, since that noun phrase cannot be referential.

There are two possible questions that a name can introduce and DP2 can answer:

1. What properties does DP1 have?

2. What is the identity of DP1?

The first question is straightforward, the second, however, is marked in this context, since the use of a proper name normally presupposes that the identity of its bearer is in the common ground.

Let us look at examples of sentence types and see how they satisfy the topiccomment requirement. In a predicational sentence, as in (31), an indefinite DP in DP2 position denotes a property and can answer the first question. In an identity statement, however, both DPs are referential. Since names refer to familiar referents and cannot denote properties, we expect that identity statements would be ungrammatical in la-constructions, which is precisely the case, as shown in (32).
(31) Saamba sacc 1-a- $\emptyset$.
Samba thief $l$-C-3SG
(32) *Osmaan Saamba 1-a- 0 .
"Samba is a thief."
Osman Samba l-C-3SG
"Osman is Samba."

In English predicational sentences, DP2 can also be a definite description, as in the sentence (Samba is the thief), when the thief is used attributively. We have seen, however, that such a structure is infelicitous in Wolof:

(33) \#Saamba sacc bi 1-a- 0 .

Samba thief the $l$-C-3SG

intended: "Samba is the thief."

Why can definite description in Wolof not denote a property? According to Heim (1982), definite descriptions come with a familiarity presupposition. They can only be felicitously used against a common ground in which the discourse referent they presuppose is already defined; in that sense, they are anaphoric. I propose that the example in (33) indicates that definite descriptions in Wolof are under pressure to be interpreted referentially, and cannot be attributive in the sense of Donnellan 1966, which renders them infelicitous as DP2 in predicational sentences. This proposal predicts that definite DPs which cancel familiarity because they presuppose uniqueness should be felicitous as DP2. This prediction is confirmed by example (34):

(34) Yusu Nduur ki gënë siiu ci musicien yi ci Senegal

Youssou N'Dour REL most famous LOC musician the LOC Senegal

$1-\mathrm{a}-\emptyset$.

$l$-C-3SG

"Youssou N'Dour is the most famous musician in Senegal." 


\section{Martina Martinović}

Definite DPs like the most famous musician in Senegal in (34) contain more information, which helps establish a unique referent (i.e. we do not need to be familiar with the referent of that DP in advance), which relaxes the familiarity presupposition of the description. I propose that such definites in Wolof do not need to refer to a familiar referent, and can denote properties.

\subsection{DP1 is a Definite Description}

In Double-DP copular sentences, DP1 can also be a definite description. In a predicational sentence, it can denote an individual, while in a specificational sentence it is proposed to be either property-denoting (Mikkelsen 2005) or an individual concept (Romero 2005). We can again ask two questions about a definite DP in DP1 position:

1. What properties does DP1 have?

2. What is the identity of DP1?

In this situation, the second question is unmarked; we do not presuppose that the identity of the referent of the definite description is known, we just know that there is a familiar referent. Crucially, familiar does not mean identifiable, or even unique.

A predicational sentence with a definite description as DP1 and an indefinite description as DP2 is, as expected, grammatical:

(35) Sacc bi jangalekat $1-\mathrm{a}-\emptyset$.

thief the teacher $l-\mathrm{C}-3 \mathrm{SG}$

"The thief is a teacher."

Specificational sentences, in which DP2 denotes an individual, are also possible la-sentences. Crucially, the example in (37) can be understood as satisfying the topic-comment structure if interpreted as an individual concept. In that case, it is a function from possible worlds in $W$ to individuals in $D$. According to this view, DP2 does indeed contribute information about DP1 - it picks out the individual who is the perpetrator of a particular theft in the real world.

(36) Sacc bi Saamba 1-a- $\emptyset$. thief the Samba $l-C-3 \mathrm{SG}$

"The thief is Samba."
(37) Sacc bi jangalekat bi $1-a-\emptyset$. thief the teacher the $l-\mathrm{C}-3 \mathrm{SG}$ "The thief is the teacher."

\subsection{Rescuing}

That the proposed analysis is on the right track is further confirmed by situations in which the requirement for the asymmetry between DP1 and DP2 can be accomplished by some mechanism, allowing one of the DPs to be reinterpreted as a 


\section{The Topic-Comment Structure in Copular Sentences: Evidence from Wolof}

different type. We already saw one such example, in (34), in which a longer definite description, which contains more information, helps establish a unique referent and thus relaxes the familiarity presupposition of the description. In this section, I present two more examples of rescuing.

In the first one, a sentence in which DP1 is a name and DP2 a definite description is for some speakers ameliorated when DP1 is made more topical. Consider the following context: A theft has occurred, and the perpetrator is unfamiliar, but he is one of the people present in the interrogation room. An eye-witness enters, points at Samba, and utters: ${ }^{7}$

(38) Saamba $a_{D E M}$ sacc bi l-a- 0 .

Samba thief the $l-\mathrm{C}-3 \mathrm{SG}$

"Samba is the thief."

I propose that pointing is the crucial element that makes (38) acceptable. Namely, by demonstratively picking out the individual denoted by DP1 out of a group of people, DP1 is made more topical then DP2, since demonstratives are higher on the Givenness Hierarchy than definite descriptions (Gundel et al. 1993). Furthermore, in this context the identity of the thief is not common ground (even though there is a familiar discourse referent), whereas the identity of Samba is.

The second example of rescuing is a situation in which both DPs are a name, but DP2 can also be understood as denoting a property. I argue that this is precisely the case in (39). Superman is not just a name, it evokes a whole set of superpowers that this individual possesses, and can therefore be property-denoting.

(39) Clark Kent Superman 1-a- 0 .

Clark Kent Superman $l$-C-3SG

"Clark Kent is Superman."

If this analysis proves to be correct, it will question the universality of Mikkelsen's claim that specificational sentences are special in having fixed informational-structural properties, as opposed to predicational sentences.

\section{Conclusion}

This paper explores the syntax of information structure of Double-DP copular sentences in Wolof, focusing on a structure in which the structural subject is obligatorily left-dislocated, and the second DP is $\mathrm{A}^{\prime}$-moved to the specifier of the complementizer $(l) a$, which occurs in many focus constructions. I argue that this creates a topic-comment structure, which imposes a particular requirement on the type of DPs that can occupy DP1 and DP2 position in the clause. In particular, I argue that DP2 must contribute new information about DP1. Despite their fixed

\footnotetext{
${ }^{7}$ Several of my consultants independently gave this scenario, insisting on the pointing gesture.
} 
Martina Martinović

information-structural profile, both predicational and specificational sentences, argued to crucially differ in terms of their information structure in several Germanic languages, can occur in this syntactic configuration in Wolof. This suggests that particular information-structural profiles are not universally associated with certain copular sentences. The proposed taxonomy of copular sentences therefore needs to be tested in languages which construct copular sentences in different ways, yet still maintain the semantic and pragmatic functions associated with various copular sentence types.

\section{References}

Adger, David and Ramchand, Gillian, 2003. Predication and equation. Linguistic Inquiry 34(3):325-359.

Akmajian, Adrian, 1970. Aspects of the grammar of focus in English. Ph.D. thesis, MIT, Cambridge, MA.

Declerck, Renaat, 1988. Studies on copular sentences, clefts and pseudo-clefts. Leuven: Leuven University Press/Foris.

den Dikken, Marcel, 2001. Specificational copular sentences and pseudoclefts. In The Blackwell Companion to Syntax, volume 4, chapter 61. Oxford: Blackwell Publishing.

Donnellan, Keith, 1966. Reference and definite descriptions. Philosophical Review 75:281-304.

Dunigan, Melynda B., 1994. On the clausal structure of Wolof. Ph.D. thesis, University of North Carolina at Chapel Hill, Chapel Hill, NC.

Green, Melanie, 2007. Focus in Hausa. Blackwell Publishing.

Gundel, Jeanette K., Hedberg, Nancy, and Zacharski, Ron, 1993. Cognitive status and the form of referring expressions in discourse. Language 96:274-307.

Heggie, Lorie, 1988. The syntax of copular structures. Ph.D. thesis, University of Southern California, Columbia, SC.

Heim, Irene, 1982. The semantics of definite and indefinite noun phrases. Ph.D. thesis, University of Massachussetts Amherst, Amherst, MA.

Heycock, Caroline, 1994. The internal structure of small clause: New evidence from inversion. In Proceedings of the 25th North East Linguistic Society.

Higgins, Francis Roger, 1979. The pseudocleft construction in English. New York: Garland.

Kihm, Alain, 1999. Focus in Wolof. A study of what morphology may do to syntax. In Georges Rebuschi and Laurice Tuller, eds., The grammar of focus, 245-273. Amsterdam: John Benjamins Publishing Company.

Laka, Itziar, 1990. Negation in syntax: On the nature of functional categories and projections. Ph.D. thesis, MIT, Cambridge, MA.

Lambrecht, Knud, 1994. Information structure and sentence form: topic, focus and the mental representations of discourse referents. Cambridge Studies in 
The Topic-Comment Structure in Copular Sentences: Evidence from Wolof

Linguistics 71., Cambridge, MA: Cambridge University Press.

Martinović, Martina, 2013. The subject/non-subject asymmetry in Wolof. In Stefan Keine and Shayne Sloggett, eds., Proceedings of the 42nd Annual Meeting of the North East Linguistic Society, volume 1, 309-322. GLSA Amherst.

Matthewson, Lisa, 1996. Determiner systems and quantificational strategies: evidence from Salish. Ph.D. thesis, The University of British Columbia.

Mikkelsen, Line, 2005. Copular clauses: specification, predication and equation. Amsterdam: John Benjamins Publishing Company.

Romero, Maribel, 2005. Concealed questions and specificational subjects. Linguistics and Philosophy 28:687-737.

Russell, Margaret A., 2006. The syntax and placement of Wolof clitics. Ph.D. thesis, University of Illinois at Urbana-Champaign, Urbana, IL.

Torrence, Harold, 2005. On the distribution of complementizers in Wolof. Ph.D. thesis, University of California, Los Angeles, Los Angeles, CA.

Torrence, Harold, 2013a. A promotion analysis of Wolof clefts. Syntax 16(2):176215.

Torrence, Harold, 2013b. The morpho-syntax of Wolof clefts: Structure and movement. In Katharina Hartmann and Tonjes Veenstra, eds., Cleft Structures. Amsterdam: John Benjamins Publishing.

Martina Martinović

Department of Linguistics

University of Chicago

1010 E 59th Street

Chicago, IL 60637

martinam@uchicago.edu 